\title{
EEG in Epilepsy: Current Perspectives
}

\author{
M. Sundaram, R.M. Sadler, G.B. Young and N. Pillay
}

\begin{abstract}
The electroencephalogram (EEG) plays an important diagnostic role in epilepsy and provides supporting evidence of a seizure disorder as well as assisting with classification of seizures and epilepsy syndromes. Emerging evidence suggests that the EEG may also provide useful prognostic information regarding seizure recurrence after a single unprovoked attack and following antiepileptic drug withdrawal. Continuous EEG video telemetry monitoring has an established role in the diagnosis of non-epileptic pseudo-seizures and in localizing the seizure focus for epilepsy surgery. Newer tools such as EEG mapping and magneto-encephalogram, although still investigational, appear potentially useful for defining the seizure focus in epilepsy. This review examines the traditional concepts of clinical EEG in the light of newly available data.
\end{abstract}

RÉSUMÉ: L'ÉEG dans l'épilepsie: perspectives actuelles. L'électroencéphalogramme (ÉEG) joue un rôle diagnostique important dans l'épilepsie et fournit des données étayant le diagnostic d'épilepsie et aidant à sa classification. Des données récentes suggèrent que l'ÉEG peut aussi fournir des informations utiles pour déterminer le pronostic quant à récurrence des crises après un épisode unique non provoqué et après le retrait de la médication antiépileptique. Le monitorage vidéo télémétrique continu de l'ÉEG a un rôle établi dans le diagnostic des pseudocrises non épileptiques et dans la localisation du foyer épileptogène en vue d'une chirurgie. Les nouveaux outils tels que la cartographie par ÉEG et le magnéto-encéphalogramme, bien qu'ils soient encore au stade expérimental, semblent potentiellement utiles pour identifier le foyer épileptogène dans l'épilepsie. Cet article de revue examine les concepts traditionnels de l'ÉEG en clinique à la lumière de données nouvelles.

Can. J. Neurol. Sci. 1999; 26: 255-262

Although the diagnosis of seizures and epileptic syndromes is primarily made from careful history and examination, the EEG remains an important investigative tool. The EEG often provides supportive evidence of seizure disorder and assists with classification of seizures and epilepsy. Moreover, EEG findings are important for determination of seizure focus and may also help with prognosis under certain circumstances.

This review examines the traditional and emerging role of EEG in epilepsy.

\section{Technical Considerations}

\section{Electrodes}

The international ten-twenty system of electrode placement, originally proposed in $1958,{ }^{1}$ is now widely used and is the recommended standard method for recording scalp EEG. The American EEG Society has recently advocated slight modifications to the original alphanumeric nomenclature ${ }^{2}$ and the recommended changes are shown in Figure 1. Note that the original T3, T4, T5 and T6 are now referred to as T7, T8, P7 and $\mathrm{P} 8$ respectively. This modification allows standardized extension of electrode placement in the subtemporal region (e.g.: F9, T9, P9, F10, T10, P10) and designates named electrode positions in the intermediate coronal lines between the standard coronal lines (e.g.: AF7, AF3, FT9, FT7, FC5, FC3, FC1, TP9, TP7, CP5, CP3, $\mathrm{CP} 1, \mathrm{PO} 7, \mathrm{PO} 3$ and so on). Additional and more closely spaced scalp electrodes - placed midway between the standard electrodes of the 10-20 system - often provide further localization of epileptiform discharges in patients with partial seizures. ${ }^{3}$ Several electrodes are available for demonstrating temporal lobe activity. Sphenoidal electrodes are particularly useful for detecting mediobasal temporal discharges and are inserted under the mandibular notch (app. 2.5 to $3 \mathrm{~cm}$ anterior to the tragus) and directed posterosuperiorly towards the foramen ovale. ${ }^{4}$ Sphenoidal electrodes have now been shown to be superior to nasopharyngeal electrodes ${ }^{5,6}$ and their proximity to

From the University of Mississippi, Jackson, MS USA (MS), Dalhousie University, Halifax, NS Canada (RMS), University of Western Ontario, ON Canada (GBY),

University of Calgary, AB Canada (NP).

RECEIVED JANUARY 7, 1999. ACCEPTED IN FINAL FORM AUGUST 9, 1999.

Reprint requests to: M. Sundaram, University of Mississippi Medical Center, Dept of Neurology, 2500 North State Street, Jackson, MS 39216, USA. 




Figure 1: Electrode nomenclature proposed by The American Clinical Neurophysiology Society (reproduced with permission from the American Neurophysiology Society.)

the foramen ovale can be assured under fluoroscopic guidance. ${ }^{7}$ Anterior "cheek" electrodes (placed on the maxilla approximately $2 \mathrm{~cm}$ anterior to the site of entry of the sphenoidal electrode) and anterior temporal electrodes (placed $1 \mathrm{~cm}$ above one third the distance from the external auditory meatus to the external canthus) are also useful for demonstrating epileptiform discharges (ED) from the temporal lobe and the yield appears comparable to that from sphenoidal electrodes. ${ }^{8,9}$

Routine scalp recordings may not show ED in approximately $10 \%$ of patients with frontal lobe seizures ${ }^{10}$ and the yield in these patients may be increased by using closely spaced electrodes such as F1, C1, F2, C2 (placed halfway between Fz/F3, Cz/C3, Fz/F4 and $\mathrm{Cz} / \mathrm{C} 4$ respectively) or supraorbital electrodes, placed $2.5 \mathrm{~cm}$ lateral to the inion on the supraorbital ridge.

\section{Digital EEG}

Digital recording machines are rapidly replacing the traditional "paper" systems. Digital EEG is particularly useful for detecting and analyzing ED as the waveforms in question can be reformatted in various montages after the recording is completed. Other advantages of digital recordings include very little storage space requirement, elimination of paper costs, automatic event detection and the ability to network different recording stations. Filter and paper speed settings with digital recordings are accurate and automatic, thereby avoiding technician oversight. Problems due to pen alignment and curvilinear effect are not seen with digital systems. A major disadvantage of digital EEG is the incompatibility of systems made by different vendors, often forcing one to resort to paper printouts for transmission of EEG data between two centers. Authors also find comparing two separate epochs somewhat cumbersome, as only limited data can be observed simultaneously on the monitor. The reader is referred elsewhere for further details on digital technology. ${ }^{11}$

\section{Activation Procedures}

\section{Hyperventilation}

Forster, in 1924, first demonstrated that hyperventilation (HV) may precipitate absence seizures in children ${ }^{12}$ and this method of activation has since become routine during EEG recordings. Although $\mathrm{HV}$ is particularly useful for demonstrating generalized epileptiform discharges, it may also activate focal epileptiform discharges in up to $10 \%$ of patients with partial epilepsies. ${ }^{13,14}$ The neuronal irritability during $\mathrm{HV}$ is considered to be due to brainstem mediated cerebral vasoconstriction induced by hypocapnia. This view, however, remains speculative and controversial. ${ }^{15}$ Hyperventilation should be avoided in patients with potential for brain damage from further vasoconstriction, e.g. malignant hypertension, subarachnoid hemorrhage, sickle cell disease or trait.

\section{Photic Stimulation}

Photic stimulation (PS) is useful for activation of generalized epileptiform discharges. Testing is generally done with stepwise increase of frequencies up to $30 \mathrm{~Hz}$ with a strobe light at a distance of 20 to $30 \mathrm{~cm}$ from the eyes. The authors recommend PS at low frequencies with eyes open and then closed. At medium and higher frequencies, stimulation should start with the eyes open, and the patient is asked to close the eyes during PS, thereby continuing with PS for a few more seconds with the eyes remaining closed. Eye closure during photic stimulation is particularly useful for augmenting ED and should routinely be used. Epileptiform discharges outlasting PS strongly suggest generalized seizure disorder, whereas those confined to the train of PS may be an incidental finding in nonepileptic subjects, especially in the setting of drug withdrawal or toxic metabolic encephalopathy, or simply represent a genetic trait. ${ }^{16,17,18,19}$ Photic stimulation is particularly useful in primary generalized epilepsy and ED may occur during PS in up to $40 \%$ of these patients. ${ }^{20}$ Recent evidence indicates that approximately a quarter to a third of EEGs with photic related ED also contain spontaneous focal or generalized ED elsewhere in the records. ${ }^{21}$ Photoparoxysmal response is more prevalent among white epileptics than black or mixed race patients. ${ }^{22}$

\section{Sleep Deprivation (SD)}

When the first EEG fails to show ED in patients with epilepsy, sleep deprived recording often helps. Several studies have convincingly documented that the chances of finding ED increase with sleep deprived recordings in both partial and generalized seizure patients of all ages. ${ }^{23-30}$ Epileptiform discharges following sleep deprivation occur both in the awake and sleep portions of the EEG. Moreover, Rowan and co-workers have shown that EEGs following sleep deprivation are more likely to contain ED than the recordings of similar length done following sedation. ${ }^{31}$ Mattson et al. ${ }^{25}$ have shown that the increase in the quantity of ED after sleep deprivation is not simply a reflection of sample time but due to direct effect of loss of sleep itself. These observations suggest that sleep deprivation augments ED not just by inducing sleep but possibly by other as yet undefined mechanisms. Authors recommend sleep deprived EEG rather than recording under sedation if the first EEG is negative.

However, several issues still remain unresolved: is all night sleep deprivation superior to half night SD? What is the ideal, 
practical duration of sleep deprived recordings? Future studies addressing these questions are awaited.

\section{Clinical Significance of Interictal ED}

\section{ED in nonepileptic subjects}

Although the presence of interictal ED generally supports the diagnosis of seizure disorder, caution is necessary in interpreting the clinical significance as ED may occur in subjects without seizures. Among healthy adults without seizure history, the frequency of ED is approximately $0.5 \% .^{32,33}$ Practically none of these healthy subjects subsequently develops seizures. "Incidental" ED occur slightly more often (app. 2\%) in subjects with a history of previous neurological insults such as trauma, stroke, craniotomy, infections, cerebral palsy or during migraine. ${ }^{34}$ Up to $14 \%$ of these patients subsequently develop seizures. In children without prior seizures, ED may occur in up to $5 \%$ and this may be as high as $8 \%$ if adequate sleep is recorded ${ }^{35-38}$ these tend to be benign rolandic or occipital spikes or generalized $3 \mathrm{~Hz}$ spike-wave discharges and likely represent incidental genetic trait. Risk of subsequent seizures in these children is around $6 \% .{ }^{36}$ Certain EEG patterns, however, almost always indicate associated clinical seizures and these include hypsarrhythmia and 1 or $2 \mathrm{~Hz}$ generalized slow spike-wave complexes.

\section{ED in the first and serial EEGs}

First standard EEGs in patients with a reasonably certain diagnosis of seizure disorder contain ED in approximately $50 \% .{ }^{39,40}$ Yield from the first EEG in children with absence seizures, however, is higher, around $75 \% .{ }^{41}$ Apart from sleep, several other factors have been shown to increase the likelihood of ED and these include i) recording within 48 hours of a seizure and ii) ongoing seizure frequency of at least one attack per month. ${ }^{40}$ The yield, however, is not significantly altered by neurological status, etiology of seizures, age of the patient and anti-epileptic drug therapy. ${ }^{40}$

Serial EEGs are often necessary for demonstrating ED. Most patients who eventually show ED do so by the fourth EEG. ${ }^{40,42}$ Recordings are persistently negative in only $8 \%$ of epileptics although there is evidence that a higher proportion of patients with partial seizures may have persistently negative serial EEGs. ${ }^{39,40}$

The above observations suggest that i) the ideal time for obtaining an EEG is the first day or two after a seizure, ii) one should consider long-term monitoring if four routine recordings have remained negative in patients with ongoing "seizures".

\section{Cognitive Changes}

Subtle and transient cognitive impairment has been demonstrated during brief "subclinical" generalized spike-wave discharges, especially during the first second. ${ }^{43-46}$ Aarts and coworkers ${ }^{45}$ have reported similar subtle cognitive impairment in some subjects during focal interictal ED. Such cognitive changes may occur in up to $50 \%$ of tested patients and may, if EDs are frequent, affect school performance and driving behavior under experimental conditions. ${ }^{47-49}$ The clinical relevance and therapeutic implications of these observations currently remain unknown.

\section{ICTAL EEG}

While interictal ED generally provides support for the diagnosis of seizure disorder, electrographic or clinical seizures during EEG confirm seizure(s). However, our experience indicates that the probability of capturing an ictal event during a routine 20 to 30 minute recording in a patient with an average of one random seizure per week is less than $1 \%$. Moreover, the scalp EEG may not reflect all of the ictal activity as this depends on i) the frequency-filtering properties of the skull and scalp, ii) the distance and orientation of the focus from the recording electrode and, iii) the surface area of the focus with respect to the recording electrode. In spite of these limitations, scalp recorded seizures provide valuable information regarding the seizure type and focus.

\section{Partial Seizures}

Partial seizures, in scalp EEGs, are metamorphic, i.e., they show two or more distinct phases. ${ }^{50-52}$ The most common patterns consist of a series of rhythmic waves, sequential spikes/sharp waves, a mixture of spikes and rhythmic waves or regional voltage attenuation. Rhythmic waves and spikes typically change in amplitude, frequency and spatial distribution as the seizure spreads to adjacent or sometimes remote areas. Finally, the discharges contract in area as the seizure ends. ${ }^{50}$ Most often the initial frequency of temporal lobe seizures is in the alpha or theta range with slower frequencies occurring in a lesser proportion. ${ }^{51}$ Extra temporal seizures, however, often start in the beta frequencies rather than slower frequencies. ${ }^{52}$ With scalp EEG, the frequency may diminish or augment, but as the seizure ends, rhythmic waves or sequential spikes change to a slow spike-wave pattern that gradually decreases in frequency. Focal electrodecremental events are of excellent localizing value, reflecting intense neuronal depolarization or high frequency firing. ${ }^{52}$ However, generalized electrodecremental events preceding focal seizures are probably not truly ictal and may represent generalized cerebral changes that predispose to focal seizure development. ${ }^{53}$ Following metamorphic seizures, there is often postictal delta slowing, suppression or activation of focal spikes. These postictal changes also have good localizing value for seizure origin and should be carefully sought. ${ }^{54}$

It is important to recognize that simple partial seizures especially those with sensory rather than motor symptoms may not be associated with discernable changes in routine scalp EEG in up to $80 \%$ of seizures. ${ }^{55}$ However, the yield in these patients may be augmented by using additional closely spaced electrodes. ${ }^{56}$

\section{Generalized seizures}

Typical absence seizures are characterized by isomorphic and stereotyped patterns that do not evolve as partial seizures. However, the spike-wave discharges may change from 3.5 or 4 $\mathrm{Hz}$ at the onset to 2 or $3 \mathrm{~Hz}$ as the seizure progresses. Also, the spike amplitude may decrease during the later part of the seizure. Atypical absence attacks frequently show gradual onset and offset with spike-wave discharges occurring at frequencies less than $3 \mathrm{~Hz}$.

Generalized tonic-clonic seizures may be preceded by diffuse polyspike-wave complexes. Ictal recordings during the tonic 
phase typically shows generalized attenuation with or without high frequency rhythmic waves that gradually increase in voltage ("epileptic recruiting rhythm") and evolve into polyspikes. The clonic phase is characterized by paroxysmal spike activity mixed with slow waves and the post-ictal period shows generalized attenuation followed by gradual recovery of rhythms. ${ }^{57}$

Myoclonic seizures are associated with 10 to $15 \mathrm{~Hz}$ polyspikes with or without slow waves, whereas tonic seizures show generalized paroxysmal fast activity or diffuse voltage attenuation preceded or followed by sharp and slow wave complexes. Generalized atonic seizures may show 2-3 Hz spikewave discharges or may not be associated with any scalp EEG change.

\section{PLEDs}

Although PLEDs have traditionally been considered "interictal", 58 there is some evidence that this pattern in some patients may be "ictal" in nature, especially when seen following traditional ictal patterns. ${ }^{59,60}$ Moreover, Reiher and co-workers reported that the "PLEDs plus pattern", consisting of periodic epileptiform activity closely followed by brief, low amplitude, stereotyped rhythmic discharges, is often associated with clinical seizures and may indeed be a foreteller of imminent seizures. ${ }^{61}$ However, whether the PLEDs or PLEDs plus pattern requires aggressive treatment similar to status epilepticus remains unclear. $^{62}$

\section{Prognosis of Epilepsy}

Routine EEG is useful for prognostic purposes in at least three situations: i) assisting in epilepsy syndrome classification, ii) predicting recurrence after the first seizure and iii) providing information on seizure relapse after anticonvulsant withdrawal.

\section{Classification of epilepsy}

The EEG provides important information for classification of various epileptic syndromes and thereby assists in predicting the natural history of the syndrome. For example, a child with normal neurological examination and rolandic spikes in EEG has a high probability of "outgrowing" seizures and may not even need treatment following isolated, infrequent seizures. Similarly, generalized 4-6 Hz spike-wave and polyspike discharges in an adolescent with seizures suggest juvenile myoclonic epilepsy of Janz: a condition with a high response rate to valproic acid or medications such as primidone or acetazoleamide when valproic acid fails.

\section{First seizure}

Prediction of recurrence after a single seizure is clinically important and many studies have addressed this question. However, differences in methodology make comparison of these studies difficult and the results still remain somewhat controversial. A meta analysis of sixteen published reports suggests that EEG abnormalities may increase the risk of recurrence after first seizure. ${ }^{63}$

A recent large prospective study of children with single unprovoked seizure ${ }^{64}$ showed that, in those without obvious etiology ("idiopathic"), the presence of epileptiform discharges in the EEG was associated with a recurrence rate of $54 \%$ whereas the rate was only $25 \%$ when the first EEG was normal. In the above study, the EEG was not of any predictive value in children with remote symptomatic seizures.

Several recent prospective studies suggest that the EEG is useful in adults with first seizure - especially among those with idiopathic seizures. ${ }^{65-67}$ The Dutch workers ${ }^{66}$ showed that when two EEGs (one baseline and one sleep deprived recording) are normal, the recurrence rate was $12 \%$ at two years, whereas in those with one or both EEGs containing ED, recurrence rate increased to $83 \%$. The Italian first seizure trial group also showed a 1.7 fold increase in seizure recurrence when the EEG contained ED. Some controversy still exists in this area as some authors maintain that the EEG findings are of no predictive value after first seizure. ${ }^{68}$

\section{Anti-epileptic drug withdrawal}

The role of EEG in predicting relapses after anti-epileptic drug withdrawal remains more controversial. Some studies show an increase in recurrence rate with abnormal EEG prior to or during the withdrawal, ${ }^{69}$ whereas others suggest that the EEG findings are of no predictive value. ${ }^{70}$ Yet others show that slowing - and not spikes - in EEG is associated with a higher recurrence in children with idiopathic seizures. ${ }^{71}$ A recent meta analysis discussing in depth various factors in predicting relapses after anti-epileptic drug withdrawal indicates that any EEG abnormality (epileptiform activity or slowing) is associated with a relative relapse risk of $1.45 .^{72}$ Other factors found to increase the relapse rate in the above meta analysis were adolescent or adult epilepsy onset (rather than childhood onset) and known remote etiology.

\section{Telemetry Monitoring}

Although the EEG remains the gold standard for confirming seizures, an actual attack or event is rare during a standard 20 to 30 minute recording. Even serial EEGs may fail to reveal ED in up to $10 \%$ of epileptics. ${ }^{39}$ When the nature of attacks or the exact seizure focus cannot be ascertained with several routine EEGs, telemetry monitoring often provides necessary additional information. With current telemetry systems, EEG data may be collected continuously for several days or even weeks. This may be done as an inpatient procedure using cable telemetry or at home/work environment with radiotelemetry. Most cable telemetry equipment also has video capability and provides an opportunity to analyze physical changes during the ictus.

Telemetry monitoring is useful: i) for confirming the nature of epileptic attacks and nonepileptic events such as pseudoseizure, ${ }^{73}$ paroxysmal movement disorders, ${ }^{74}$ and sleep disorders, ${ }^{75}$ ii) for exact classification of seizures prior to appropriate therapy, ${ }^{76}$ iii) for determination of seizure focus in patients with atypical features (e.g. frontal lobe seizures, gelastic seizures), ${ }^{77,78}$ or for presurgical evaluation, ${ }^{79}$ iv) for assessing the response to anticonvulsant therapy, ${ }^{80,81}$ and $v$ ) for research purposes, e.g. analysis of the relationship between the quantity of interictal spikes and clinical seizures. ${ }^{82,83}$

Video telemetry is generally indicated when visual analysis of physical changes during the event is necessary as in pseudoseizure, frontal lobe seizures, and paroxysmal movement disorders. Ambulatory monitoring without video may be 


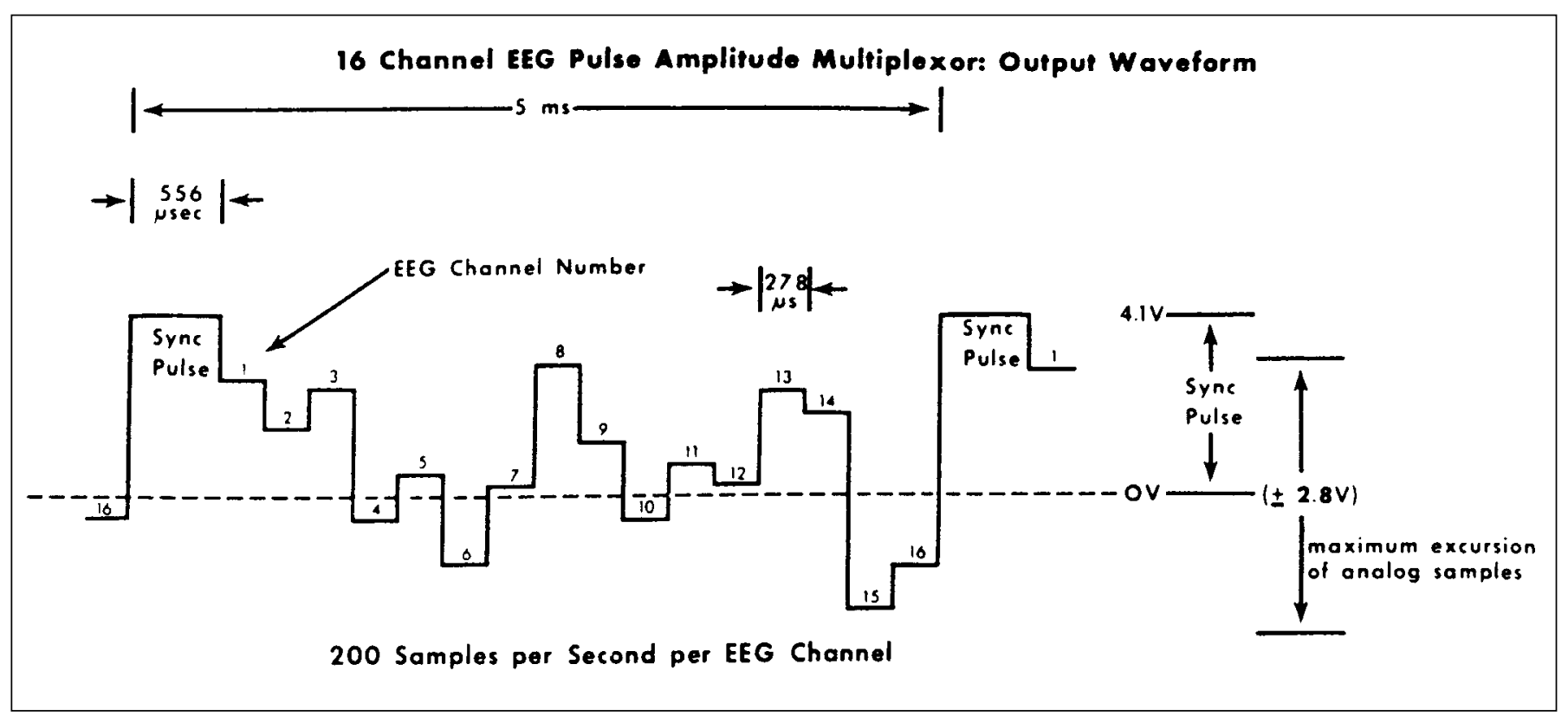

Figure 2: Summary of multiplexing sixteen channels of EEG data using time-division method (reproduced from Ives JR, Thompson CJ, Gloor P. Seizure monitoring: a new tool in electroencephalograph. Electroencephalogr Clin Neurophysiol 1976; 41:422-427.with permission from Elsevier Science).

sufficient for confirming the nature of events such as syncope or absence attacks.

The following is a summary of the principles involved in telemetry technology: long term monitoring requires some amount of patient mobility and this often results in electrostatic artifacts from cable motion and friction between the insulating materials of the electrode leads. These artifacts, in telemetry, are minimized by attaching a miniature preamplifier close to the patient, thereby keeping the length of the leads from scalp electrodes to the preamplifier short. Several channels of signals thus amplified in the preamplifier are then encoded onto a single channel and this process is called "multiplexing" (Figure 2). Multiplexed signals then can either be carried along a flexible cable and stored in a nearby station ("cable telemetry"). Alternately, multiplexed signals could be relayed to a distant receiving station using a radiotransmitter ("radiotelemetry"). At the receiving station the transmitted signals are stored in the audio tract of a magnetic video tape or as a digital signal on an optical disc. In some ambulatory systems, EEG data are stored without multiplexing in a small cassette recorder carried by the patient. Recent advances in technology now enable us to record and store even video signals digitally with significant improvement in clarity.

Digital time signals can be encoded in the current systems for correlating events with EEG data. The patient (or relative) presses an event marker during the ictus, thereby registering the time, and this provides the technologist with a list of events. Automated seizure detection devices are also available and these ensure that the events are not missed even if the event marker is not manually pressed. Most current available telemetry systems can process up to 128 channels of EEG data.

In recent years, portable telemetry systems with simultaneous video capability have become available and provide good quality monitoring in home or work environment. ${ }^{84}$ This method would be cost saving as inpatient expenses are avoided. Video telemetry may also be done, especially for children, for three or four half or full days in an outpatient setting until the habitual event or suspected EEG abnormality has been recorded.

Additional information on telemetry technology may be found elsewhere..$^{85,86}$

When carefully used, telemetry provides clinically useful additional information in approximately two thirds of monitored patients. ${ }^{87}$

\section{NeWER METhODS}

\section{Brain mapping}

Brain mapping refers to quantification and topographic display of various EEG frequencies or evoked potentials. This procedure requires special technical expertise for identification of artifacts and drowsiness as well as a thorough knowledge of statistical analysis and computer data processing. Interpretation thus requires a clear understanding of the pitfalls and limitations of this technique. ${ }^{88,89}$ Currently, brain mapping is primarily a research tool with limited clinical applications. ${ }^{90}$ Potential areas of clinical use include detection of subtle EEG frequency alterations in mild organic encephalopathies (e.g. Alzheimer's disease) or underlying ischemia and in determination of spike source in epilepsy.

In epilepsy, brain mapping appears to be a promising tool for determination of the source of focal interictal spikes in benign rolandic epilepsy of childhood ${ }^{91}$ and temporal lobe epilepsy. ${ }^{92}$ A recent paper by Ebersole describes the process involved in the analysis of spatial distribution of voltage fields and localization of spike generators in several patients with temporal lobe epilepsy. ${ }^{93}$ Thus, brain mapping may provide another noninvasive localization technique prior to epilepsy surgery, but additional studies are necessary. 


\section{Magneto-encephalogram (MEG)}

Traditional EEG records the extracellular electrical current, whereas MEG detects the corresponding magnetic fields. The neurons in the walls of the sulci produce current dipoles that are tangential to the skull and these are detected by MEG. However, neurons at the tip of the gyri are radial to the skull and do not contribute to MEG. Although the EEG records the electrical currents from both gyral and sulcal neurons, these currents are often distorted as they pass through various intervening tissues. Magnetic fields, however, pass through these tissues without any distortion and are easily recorded by MEG. Moreover, MEG measurements are absolute - rather than differential - thereby eliminating any active reference contamination. Thus, MEG offers a relatively simple, noninvasive, but still expensive method for monitoring the activity of the brain. Several studies show that the spatial and temporal resolution of spikes especially those at the depths - is superior with MEG than conventional EEG. ${ }^{93,94}$ Thus MEG appears to be another noninvasive tool in epilepsy for localization of spikes. With rapidly evolving technology, cheaper and more mobile MEG systems should be available for wider use within the next decade.

\section{SUMMARY}

After almost 70 years since Berger showed the usefulness of EEG in man, this procedure still remains the "gold standard" for the diagnosis of seizures and epilepsy. The role of EEG has expanded in recent years and the test now plays an important role in predicting seizure recurrence among patients with newly diagnosed epilepsy and during anti-epileptic drug withdrawal. Rapid advances in technology have made digital equipment and continuous monitoring more widely available and at the same time providing better quality recordings than ever before. Magnetoencephalography and brain mapping are rapidly evolving and appear to be promising for precise localization of spikes and detection of subtle non-epileptiform abnormalities in the brain.

\section{REFERENCES}

1. Jasper H. Report of committee on methods of clinical exam in EEG. Electroencephalogr Clin Neurophysiol 1958; 10:370-375.

2. American EEG Society. Guidelines for standard electrode position nomenclature. J Clin Neurophysiol 1991; 8:200-2.

3. Morris HH, Luders HL, Lesser RP, Dinner DS, Wyllie E. Value of closely spaced electrodes in the localization of epileptiform foci: a study of 26 patients with complex partial seizures. Electroencephalogr Clin Neurophysiol 1987; 63:107-11.

4. Rovit RL, Gloor P, Rassmussen T. Sphenoidal electrodes in the electrographic study of patients with temporal lobe epilepsy. J Neurosurg 1961; 18:151-158.

5. Sperling MR, Mendius JR, Engel Jr. J. Mesial temporal spikes: a simultaneous comparison of sphenoidal, nasopharyngeal and ear electrodes. Epilepsia 1986; 27:81-86.

6. Sadler RM, Goodwin J. Multiple electrodes for detecting spikes in partial complex seizures. Can J Neurol Sci 1989; 16:326-329.

7. Kanner AM, Ramirez L, Jones JC. The utility of placing sphenoidal electrodes under the foramen ovale with fluoroscopic guidance. J Clin Neurophysiol 1995; 12:72-81.

8. Homan RW, Jones MC, Rowat S. Anterior temporal electrodes in complex partial seizures. Electroencephalogr Clin Neurophysiol 1988; 70:105-109.

9. Krauss GL, Lesser RP, Fisher RS, Arroyo S. Anterior "cheek" electrodes are comparable to sphenoidal electrodes for the identification of ictal activity. Electroencephalogr Clin Neurophysiol 1992; 83:333-338.

10. Quesney LF. Seizures of frontal lobe origin. In: Meldrum B, Pedley TA. eds: Recent Advances in Epilepsy, No 3. Edinburgh: Churchill-Livingstone 1986; 81-110.

11. Gorney DS. The practical guide to digital EEG. Am J EEG Technol 1992; 32:260-289.

12. Forster O. Hyperventilations epilepsie Dtsch Z. Nervenheilkd 1924; 83:347-356.

13. Miley CE, Forster FM. Activation of partial complex seizures by hyperventilation. Arch Neurol 1977; 34:371-373.

14. Gabor AJ, Ajmone-Marsan C. Coexistence of focal and bilateral diffuse paroxysmal discharges in epileptics: clinical electrographic study. Epilepsia, 1969; 10:453-472.

15. Patel VM, Maulsby RL. How hyperventilation alters the electroencephalogram: a review of controversial viewpoints emphasizing neurophysiological mechanisms. J Clin Neurophysiol, 1987; 4:101-120.

16. Newmark ME, Penry JK. Photosensitivity and Epilepsy: A Review. 1979; New York: Raven Press.

17. Reilly EW, Peters JF. Relationship of some varieties of electroencephalographic photosensitivity to clinical convulsive disorders. Neurology 1973; 23:1040-1057.

18. Doose H, Gerken H, Hien-volpel KF, Volzke E. Genetics of photosensitive epilepsy. Neuropediatrie 1969; 1:56-73.

19. Kooi K, Thomas MH, Mortenson FN. Photoconvulsive and photomyoclonic responses in adults. An appraisal of their clinical significance. Neurology 1960; 10:1051-1058.

20. Gastaut H, Trevisan C, Naquet R. Diagnostic value of electroencephalographic abnormalities provoked by intermittent photic stimulation. Electroencephalogr Clin Neurophysiol 1958; 10:194-195.

21. Gilliam FG, Chiappa KH. Significance of spontaneous epileptiform abnormalities associated with a photoparoxysmal response. Neurology 1995; 45:453-456.

22. de Graaf AS, Lombard CJ, Claassen DA. Influence of ethnic and geographic factors on the classic photoparoxysmal response in the electroencephalogram of epilepsy patients. Epilepsia 1995; 219:23.

23. Rodin EA, Luby ED, Gottlieb JS. The electroencephalogram during prolonged experimental sleep deprivation. Electroencephalogr Clin Neurophysiol 1962; 14:544-551.

24. Bennett DR, Mattson RH, Ziter FA, Calverly JR, Liske EA, Pratt RL. Sleep deprivation: neurological and electroencephalographic effects. Aerospace Med 1964; 35:888-890.

25. Mattson RH, Pratt KL, Calverly JA. Electroencephalograms of epileptics following sleep deprivation. Arch Neurol 1965; 13:310-315.

26. Pratt KL, Mattson RH, Weikers NJ, Williams R. EEG activation of epileptics following sleep deprivation: a prospective study of 114 cases. Electroencephalogr Clin Neurophysiol 1968; 24:1115.

27. Geller MR, Gourdji N, Christoff N, Fox E. The effects of sleep deprivation on the EEGs of epileptic children. Dev Med Child Neurol 1969; 11:771-776.

28. Spadetta V. La Privazivne di Sonno nella diagnosi elettroencefalografica di epilessia. Act Neurol (Napoli) 1971; 26:7-13.

29. Scollo-Lavizzari G, Pralle W, De La Cruz N. Activation effects of sleep deprivation and sleep in seizure patients. Eur Neurol 1975; $13: 1-5$.

30. Degan R. A study of the diagnostic value of waking and sleep EEGs after sleep deprivation in epileptic patients on anticonvulsive therapy. Electroencephalogr Clin Neurophysiol 1980; 49:577584.

31. Rowan J, Veldhuisen RJ, Nagelkerke NJD. Comparative evolution of sleep deprivation and sedated sleep EEGs as diagnostic aids in epilepsy. Electroencephalogr Clin Neurophysiol 1982; 54:357364.

32. Robin JJ, Tolan GD, Arnold JW. Ten year experience with abnormal EEGs in asymptomatic adult males. Aviation Space Env Med 1978; 49: 732-736. 
33. Gregory RP, Oates T, Merry RTG. Electroencephalogram epileptiform abnormalities in candidates for aircrew training. Electroencephalogr Clin Neurophysiol 1993; 86:75-77.

34. Zivin L, Ajmone-Marsan C. Incidence and prognostic significance of epileptiform activity in the EEG of nonepileptic subjects. Brain 1968; 91:751-778.

35. Eeg-Olofsson O, Peterson I, Sellden V. The development of the electroencephalogram in normal children from the age of one through fifteen years. Neuropaediatrie 1971; 4:375-404.

36. Cavazzuti GB, Cappella L, Nalin A. Longitudinal study of epileptiform EEG patterns in normal children. Epilepsia 1980 21:43-55.

37. Iida N. Okada S, Tsuboi T. EEG abnormalities in nonepileptic patients. Fol Psychiatr Neurol Jpn 1985; 39:43-58.

38. Okubo Y, Matsuura M, Asai T, Asai K, Kato M, et al. Epileptiform EEG discharges in healthy children: prevalence, emotional and behavioral correlates and genetic influences. Epilepsia 1994; 35:832-841.

39. Ajmone-Marsan C, Zivin LS. Factors related to the occurrence of typical paroxysmal abnormalities in the EEG records of epileptic patients. Epilepsia 1970; 11:361-381.

40. Sundaram M, Hogan T, Hiscock M, Pillay N. Factors affecting interictal spike discharges in adults with epilepsy. Electroencephalogr Clin Neurophysiol 1990; 75; 358-360.

41. Goodin DS, Aminoff MJ. Does the interictal EEG have a role in the diagnosis of epilepsy? Lancet 1984; i:837-839.

42. Salinsky M, Kanter R, Dasheiff RM. Effectiveness of multiple EEGs in supporting the diagnosis of epilepsy: an operational curve. Epilepsia 1987; 28:331-334.

43. Mirsky AF, Van Buren JM. On the nature of the "Absence" in centroencephalic epilepsy: a study of some behavioral electroencephalographic and autonomic factors. Electroencephalogr Clin Neurophysiol 1965; 18:334-348.

44. Browne TR, Penry JK, Porter RJ, Dreifuss FE. Responsiveness before, during and after spike-wave paroxysms. Neurology 1974; 24:659-665.

45. Aarts JHP, Binnie CD, Smit AM, Wilkins AJ. Selective cognitive impairment during focal and generalized epileptiform EEG activity. Brain 1984; 107:293-308.

46. Binnie CD, Marston D. Cognitive correlates of interictal discharges. Epilepsia 1992; 33 (Suppl. 6):S11- S17.

47. Kasteleijn-Nolst Trenite DGA, Riemersma JBJ, Binnie CD, Smit AM, Meinardi $\mathrm{H}$. The influence of subclinical epileptiform EEG discharges on driving behavior. Electroencephalogr Clin Neurophysiol 1987; 67: 167-170.

48. Kasteleijn-Nolst Trenite DGA, Bakker DJ, Binnie CD, Buerman A, Van Raaij M. Psychological effects of subclinical epileptiform discharges: scholastic skills. Epilepsy Res 1988; 2:111-116.

49. Siebelink BM, Bakker DJ, Binnie CD, Kasteleijn-Nolst Trenite DGA. Psychological effects of subclinical epileptiform EEG discharges in children: general intelligence tests. Epilepsy Res 1988; 2:117-121

50. Blume WT, Young GB, Lemieux JF. EEG morphology of partial epileptic seizures. Electroencephalogr Clin Neurophysiol 1984; 57:295-302.

51. Geiger LR, Harner RN. EEG patterns at the time of focal seizure onset. Arch Neurol 1978; 35:276-286.

52. Sharbrough FW. Scalp recorded ictal patterns in focal epilepsy. J Clin Neurophysiol 1993; 10:262-267.

53. Alarcon G, Binnie CD, Elwes RDC, Polkey CE. Power spectrum and intracranial EEG patterns at seizure onset in partial epilepsy. Electroencephalogr Clin Neurophysiol 1995; 94:326-337.

54. Kaibara M, Blume WT. The postictal electroencephalogram. Electroencephalogr Clin Neurophysiol 1988; 70:99-104.

55. Devinsky O, Kelley K, Porter RJ, Theodore WH. Clinical and electroencephalographic features of simple partial seizures. Neurology 1988; 38:1347-1352.

56. Bare MA, Burnstine TH, Fisher RS, Lesser RP. Electroencephalographic changes during simple partial seizures. Epilepsia 1994; 35:715-720.

57. Gastaut H, Broughton R. Epileptic Seizures. Clinical and Electrographic Seizures: Diagnosis and Treatment. Springfield, Ill: Charles C. Thomas 1972.
58. Young GB, Goodenough P, Jacono V, Schieven JR. Periodic lateralized epileptiform discharges (PLEDs): electrographic and clinical features. Am J EEG Technol 1988; 28: 1-13.

59. Handforth A, Cheng JT, Mandelkern MA, Treiman DM. Markedly increased mediotemporal lobe metabolism in a case with PLEDs: further evidence that PLEDs are a manifestation of partial status epilepticus. Epilepsia 1994; 35:876-881.

60. Treiman DM. Generalized convulsive, nonconvulsive and focal status epilepticus. In: Feldman E. Ed. Current Diagnosis in Neurology. St. Louis: Mosby-Yearbook, 1994: 11-18.

61. Reiher J, Rivest J, Grand'Maison F, Leduc CP. Periodic lateralized epileptiform discharges with transitional rhythmic discharges: association with Seizures. Electroencephalogr Clin Neurophysiol 1991; 78:12-17.

62. Treiman DM. Electroclinical features of status epilepticus. J Clin Neurophysiol 1995; 12:343-362.

63. Berg AT, Shinnar S. The risk of seizure recurrence following a first unprovoked seizure: a quantitative review. Neurology 1991; 41: 965-972.

64. Shinnar S, Kang H, Berg AT, Goldensohn ES, Hauser WA, Moshe SL. EEG abnormalities in children with a first unprovoked seizure. Epilepsia 1994; 35: 471-476.

65. Hauser WA, Rich SS, Annegers JF, Anderson VE. Seizure recurrence after a 1st unprovoked seizure: an extended follow up. Neurology 1990; 40: 1163-1170.

66. Van Donselaar CA, Schimsheimer RJ, Geerts AT, Declerck AC. Value of the electroencephalogram in adults with untreated idiopathic first seizures. Arch Neurol 1992; 42: 231-287.

67. First seizure trial group. Randomized clinical trial on the efficacy of anti-epileptic drugs in reducing the risk of relapse after a first unprovoked tonic-clonic seizure. Neurology 1993; 43: 478-483.

68. Hopkins A, Garman A, Clarke C. The first seizure in adult life: value of clinical features, electroencephalography, and computerized tomographic scanning in prediction of seizure recurrence. Lancet 1988; 1: 721-726.

69. Tennison MT, Greenwood R, Lewis D, Thorn M. Discontinuing antiepileptic drugs in children with epilepsy. A comparison of a six week and nine month taper period. N Engl J Med 1994; 330: 1407-1410.

70. Medical Research Council Antiepileptic Drug Withdrawal Study Group. Prognostic index for recurrence of seizures after remission of epilepsy. Br Med J 1993; 306: 1374-1378.

71. Shinnar S. Berg AT, Moshe SL, Kang H, O'Dell C, et al. Discontinuing antiepileptic drugs in children with epilepsy: a prospective study. Ann Neurol 1994: 35:534-545.

72. Berg AT, Shinnar S. Relapse following discontinuation of antiepileptic drugs: a meta analysis. Neurology 1994; 44:601-8.

73. Gates JR, Ramani V, Whalen SM, Loewenson R. Ictal characteristics of pseudoseizures. Arch Neurol 1985; 42:11831187.

74. Donat JF, Wright FS. Episodic symptoms mistaken for seizures in the neurologically impaired child. Neurology 1990; 40:156-157.

75. Aldrich MS, Jahnke B. Diagnostic value of video-EEG polysomnography. Neurology 1991; 41:1060-1066.

76. Penry JK, Porker RJ, Dreifuss FE. Simultaneous recording of absence seizures with videotape and electroencephalography. Brain 1975; 98:427-440.

77. Quesney LF, Constrain M, Fish DR, Rasmussen T. The clinical differentiation of seizures arising in the parasagittal and anterolaterodorsal frontal cowexities. Arch Neurol 1990; 47:477479.

78. Arfel G, Laurette G. Evolution of paroxysmal discharges assessed by radiotelemetry in an infant with gelastic seizures. Electroencephalogr Clin Neurophysiol 1975; 39:554.

79. Lesser RP, Fisher RS, Kaplan P. The evaluation of patients with intractable complex partial seizures. Electroencephalogr Clin Neurophysiol 1989; 73:381-388.

80. Rowan AJ, Pippenger CE, McGregor PA, French JH. Seizure activity and anticonvulsant drug concentration - 24 hour sleep waking studies. Arch Neurol 1975; 32:281-288.

81. Rowan AJ, Binnie CD, DeBeer-Pawlikowski NKB, et al. Sodium valproate: serial monitoring of EEG and serum levels. Neurology 1979; 29:1450-1459. 
82. Stevens JR, Lonsbury BL, Goel SL. Seizure occurrence and interictal spike interval-telemetered electroencephalogram studies. Arch Neurol 1972; 26:409-19.

83. Gotman J, Marciani MG. Electroencephalographic spiking activity, drug levels and seizure occurrence in epileptic patients. Ann Neurol 1985; 17:597-603.

84. Leroy RF, Rao KK, Voth BJ. Intensive neurodiagnostic monitoring in epilepsy using ambulatory cassette EEG with simultaneous video recording. In: Ebersole JS, ed. Ambulatory EEG Monitoring. New York: Raven Press, 1998.

85. Ives JR, Thompson CJ, Gloor P. Seizure monitoring: a new tool in electroencephalograph. Electroencephalogr Clin Neurophysiol 1976; 41:422-427.

86. Kamp A. Amplification and transmission of the EEG. In: Long Term Monitoring in Epilepsy, Eds, J. Gotman, J.R. Ives, P. Gloor. Electroencephalogr Clin Neurophysiol 1985; 37:27-60.

87. Binnie CD, Rowan AJ, Overweg J, Meinardi H, Wisman T, et al. Telemetric EEG and video monitoring in epilepsy. Neurology 1981; 31:298-303.
88. Epstein CM. Computerized EEG in the courtroom. Neurology 1994; 44: 1566-1569.

89. Nuwer MR, Hauser HM. Erroneous diagnosis using EEG discriminant analysis. Neurology 1994; 44: 1998-2000.

90. Lopes da Silva FH. A critical review of clinical applications of topographic mapping of brain potentials. J Clin Neurophysiol $1990 ; 7: 535-551$

91. Wong PKH. Stability of source estimates in rolandic spikes. Brain Topogr 1989:2:31-36.

92. Ebersole, JS. Non-invasive localization of the epileptogenic focus by EEG dipole modeling. Acta Neurol Scand 1994; Supp 152:20-28.

93. Sutherling WW, Barth DS. Magneto-encephalography in clinical epilepsy studies. The UCLA experience. Adv Neurol 1990; 54:231-245.

94. Paetau R, Kajola M, Karhu J, Nousiainen V, Partanen J, et al. Magnetoencephalographic localization of epileptic cortex - impact on surgical treatment. Ann Neurol 1992; 32:106-109. 